\section{Analysis of Oxidized DNA Fragments by Gel Electrophoresis}

This unit describes electrophoretic techniques that can be used to characterize the chemistry of deoxyribose oxidation in DNA. The techniques exploit the unique electrophoretic mobility of DNA fragments possessing the various products of deoxyribose oxidation on their termini. Oxidation of each position in deoxyribose produces a spectrum of different products, some of which remain covalently attached to the DNA strand (Fig. 10.8.1). These fragments either accelerate (e.g., 3'-phosphoglycolate) or retard (e.g., $5^{\prime}$-nucleoside aldehyde) the mobility of the DNA fragment in a denaturing polyacrylamide gel. By altering the mobility characteristics with several simple chemical derivatizations, deoxyribose oxidation at the $3^{\prime}-$, $4^{\prime}$-, and $5^{\prime}$-positions can be defined and quantified with great accuracy. This technique has been used to characterize the chemistry of deoxyribose oxidation produced by radiation (Henner et al., 1983), rhodium complexes (Sitlani et al., 1992), bleomycin (Steighner and Povirk, 1990), neocarzinostatin (Dedon and Goldberg, 1990; Kappen et al., 1991), calicheamicin (Hangeland et al., 1992; Dedon et al., 1993), esperamicin (Christner et al., 1992; Yu et al., 1994), C-1027 (Xu et al., 1994), and Fe-EDTA (Balasubramanian et al., 1998), among other oxidizing agents.

\section{DETERMINATION OF 4'-OXIDATION OF DEOXYRIBOSE}

Oxidation of the $4^{\prime}$ position of deoxyribose by a variety of oxidizing agents and DNAdamaging drugs results in the formation of either of two sets of products, as shown in Figure 10.8.1. One set consists of a phosphoglycolate residue attached to the $3^{\prime}$ end of the broken DNA strand. This negatively charged two-carbon fragment increases the mobility

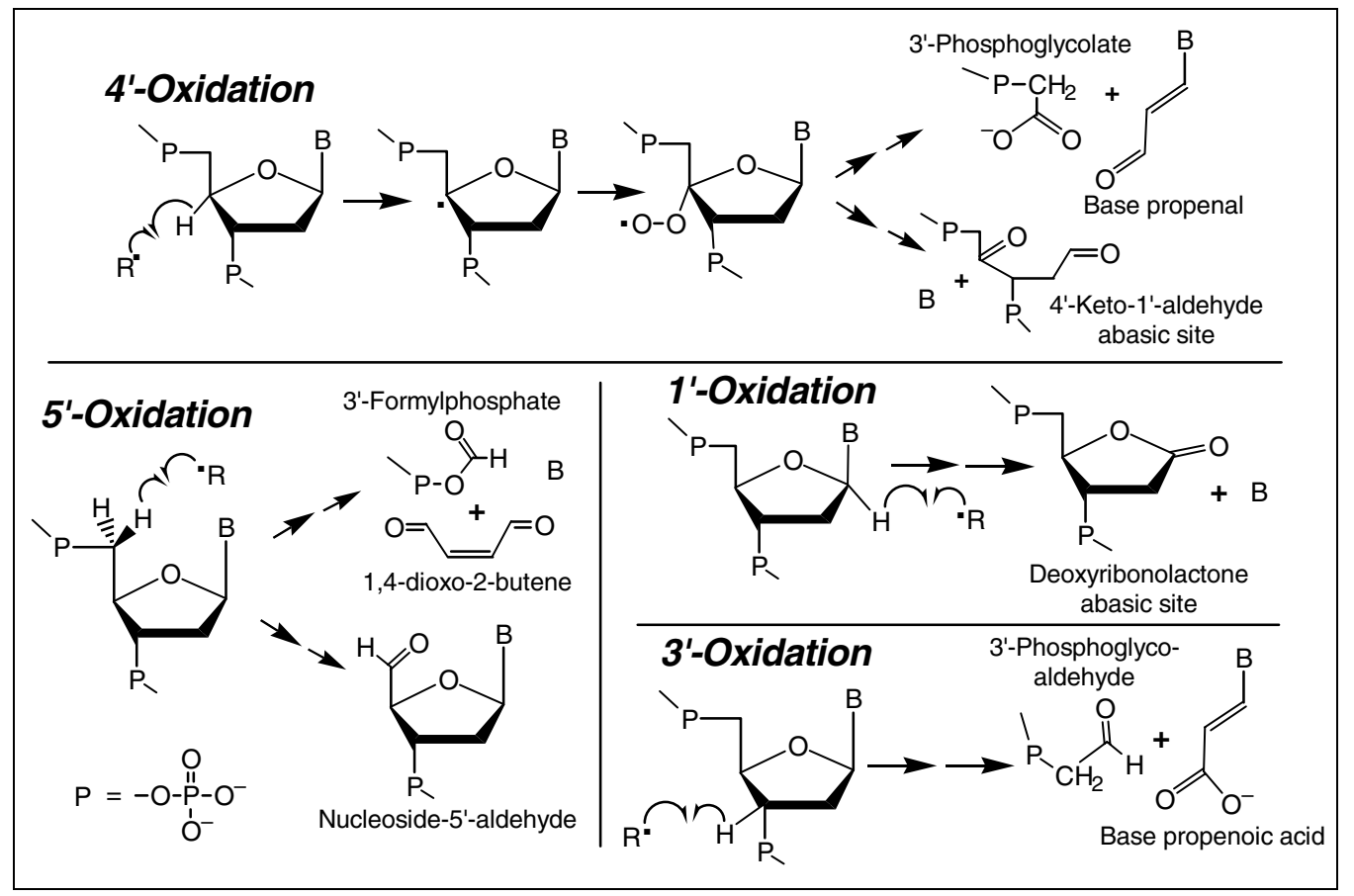

Figure 10.8.1 Products formed by oxidation of deoxyribose in DNA. This compilation is based on studies performed with the DNA-cleaving antibiotic bleomycin and members of the enediyne antibiotic family (Dedon and Goldberg, 1992), as well as DNA-cleaving rhodium complexes (Sitlani et al., 1992).

Contributed by Mohamad Awada and Peter C. Dedon Current Protocols in Nucleic Acid Chemistry (2001) 10.8.1-10.8.11

Copyright $\odot 2001$ by John Wiley \& Sons, Inc.
UNIT 10.8

BASIC

PROTOCOL 1

Purification and Analysis of Synthetic Nucleic Acids and Components 
of the DNA fragment in a sequencing gel. The other product consists of a $4^{\prime}$-keto-1'-aldehyde abasic site (Fig. 10.8.1). By treatment with hydrazine, this product can be converted to a phosphopyridazine residue attached to the $3^{\prime}$ end of the resulting break, which retards the migration of the fragment on a sequencing gel. The presence of one or both of these oxidation products is consistent with oxidation of the $4^{\prime}$ position of deoxyribose. With the anticancer drug bleomycin, the ratio of the two products serves as an index of oxygen tension, since one pathway is oxygen-dependent while the other is not (Stubbe and Kozarich, 1987). The ratio may also serve as an index of the reducing environment in the vicinity of the lesion, given the decrease in the ratio of glycolate to abasic site as thiol concentrations increase (Dedon and Goldberg, 1992).

\section{Materials}

$5^{\prime}-{ }^{32} \mathrm{P}$-end-labeled DNA or duplex oligonucleotide (e.g., see CPMB UNIT 3.10)

$1 \mathrm{mg} / \mathrm{mL}$ sonicated calf thymus DNA (UNIT 8.1)

$50 \mathrm{mM}$ Tris.Cl (APPENDIX 2A), HEPES, or other buffer (not phosphate), containing 1 $\mathrm{mM}$ EDTA, $\mathrm{pH} 7$

DNA-damaging agent

$3 \mathrm{M}$ sodium acetate, $\mathrm{pH} 7$ (APPENDIX 2A)

$100 \%$ (v/v) ethanol, $-20^{\circ} \mathrm{C}$

$70 \%$ and $95 \%(\mathrm{v} / \mathrm{v})$ ethanol

$1 \mathrm{M}$ putrescine dihydrochloride (Prepare immediately before use)

$1 \mathrm{M}$ aqueous hydrazine (Prepare immediately before use)

Formamide sequencing gel loading buffer without $\mathrm{NaOH}$ (e.g., see CPMB UNIT 7.4A)

Maxam-Gilbert sequencing markers prepared from the end-labeled DNA (e.g., see CPMB UNIT 7.5)

$20 \%$ to $25 \%$ (w/v) polyacrylamide gel, $0.4 \mathrm{~mm}$ thick, containing urea and TBE electrophoresis buffer

Tris/borate/EDTA (TBE) electrophoresis buffer (see, e.g., CPMB UNIT 7.6)

Sequencing gel fixing solution (10\% methanol, $10 \%$ acetic acid)

Sephadex G-25 spin column (e.g., see CPMB UNIT 3.4)

Sequencing gel apparatus $(30 \times 40 \mathrm{~cm})$ with $0.4 \mathrm{~mm}$ spacers and $2000 \mathrm{~V}$ power supply

Boiling water bath

Whatman 3MM paper, larger than the size of the gel

Sequencing gel drier, solvent trap, and vacuum pump (e.g., see CPMB UNIT 7.6)

$\mathrm{X}$-ray film or phosphor imager

CAUTION: Hydrazine is extremely toxic. It should be handled with gloves, in a fume hood, and disposed of properly. Methods of disposal may vary between different institutions. Consult with the institution's environmental safety office for the preferred means of storage and disposal of hydrazine.

\section{Perform DNA damage reaction}

1. Prepare $48 \mu \mathrm{L}$ of a solution containing $\sim 50,000 \mathrm{cpm}$ of ${ }^{32} \mathrm{P}$-labeled DNA, $31.2 \mu \mathrm{g} / \mathrm{mL}$ calf thymus DNA (add from $1 \mathrm{mg} / \mathrm{mL}$ stock), and $50 \mathrm{mM}$ buffer.

2. Add $2 \mu \mathrm{L}$ of a solution containing the DNA-damaging agent and allow the reaction to proceed at the desired temperature.

The final concentration of the DNA-damaging agent must be determined empirically, and should provide an adequate band intensity for sequencing gel analysis. However, care should be taken to avoid loss of more than 50\% of the parent DNA substrate. For example, 
Dedon et al. (1993) used calicheamicin (final concentration, $0.2 \mu M$ ) with ${ }^{32}$ P-labeled DNA

to induce damage adequate for visualization on sequencing gels.

3. At the desired end-point, stop the reaction as necessary and purify the DNA either by ethanol precipitation or by passage of the reaction mixture over a Sephadex G-25 spin column (to remove salts, metals, etc.) followed by ethanol precipitation. Perform ethanol precipitation as follows:

a. Add $1 / 10$ vol $3 \mathrm{M}$ sodium acetate and then 2 to 3 vol $100 \%$ ethanol, $-20^{\circ} \mathrm{C}$.

b. Centrifuge $\geq 30 \mathrm{~min}$ at $16,000 \times \mathrm{g}, 4^{\circ} \mathrm{C}$.

c. Carefully decant the supernatant or remove it with a pipet. Rinse the pellet with $70 \%$ ethanol (to remove salts), and then rinse again with $95 \%$ ethanol.

The need to terminate the DNA-damaging reaction depends entirely on the damaging species and its concentration in the reaction mixture (i.e., for agents present in vast excess of the DNA substrate). For example, enediyene antibiotics are labile species that produce only one DNA-damage event per molecule (Dedon et al., 1993). Reactions with enediyenes are thus self-terminating. However, reactions with redox cycling metals such as Fe(EDTA) may require termination with a metal-chelating agent, such as thiourea in this case (Balasubramanian et al., 1998), to avoid excessive DNA damage.

\section{Prepare DNA sample for chemical derivatization reactions}

4. Dry the sample under vacuum and resuspend the DNA in $30 \mu \mathrm{L}$ deionized water.

5. Split the sample into three $10-\mu \mathrm{L}$ portions and place one portion on ice as the control.

6. To another $10-\mu \mathrm{L}$ portion, add $1 / 10$ vol of $1 \mathrm{M}$ putrescine dihydrochloride, and incubate the sample for $1 \mathrm{hr}$ at $37^{\circ} \mathrm{C}$ to cleave abasic sites.

7. To the final $10-\mu \mathrm{L}$ portion, add $1 / 10 \mathrm{vol}$ of $1 \mathrm{M}$ hydrazine solution and incubate the sample $1 \mathrm{hr}$ at room temperature to convert the $4^{\prime}$-keto-1'-aldehyde abasic site to a phosphopyridazine residue.

The phosphoglycolate, if present will form in all three samples.

8. Precipitate all three DNA samples with ethanol as described in step 3.

9. Dry the DNA under vacuum and dissolve in $4 \mu \mathrm{L}$ formamide sequencing gel loading buffer.

It is important to use a loading buffer that is not alkaline (e.g., that contains no $\mathrm{NaOH}$ ). Alkaline $p H$ will cause hydrolysis of abasic sites in DNA and lead to erroneous conclusions regarding the quantity of phosphate-ended fragments and abasic sites in the damaged DNA.

\section{Load and run sequencing gel}

10. Prerun a $20 \%$ to $25 \%$ polyacrylamide gel ( $0.4 \mathrm{~mm}$ thick) at 1500 to $2000 \mathrm{~V}$ for $\sim 1$ $\mathrm{hr}$ to heat the gel and glass plates to $40^{\circ}$ to $50^{\circ} \mathrm{C}$. Use TBE electrophoresis buffer as the running buffer.

11. Place a 2- $\mu$ l aliquot of each of the DNA samples and Maxam-Gilbert sequencing markers in a capped centrifuge tube, place tubes in a boiling water bath for $1 \mathrm{~min}$, and plunge the tubes into ice water.

12. Load the 2- $\mu \mathrm{L}$ DNA samples onto the gel, bracketing the samples with $2-\mu \mathrm{L}$ aliquots of the Maxam-Gilbert sequencing markers containing roughly equal quantities of radioactivity as the DNA samples.

13. Using the bromphenol blue and xylene cyanol dyes as DNA size indices, run the sequencing gel at the maximal voltage that does not cause the temperature of the glass

Purification and Analysis of Synthetic Nucleic Acids and Components

10.8 .3 
plates to exceed $60^{\circ} \mathrm{C}$, and until the DNA fragment size of interest has migrated to within $10 \mathrm{~cm}$ of the bottom of the gel.

It is important to run the gel until the DNA fragment size of interest has migrated as far as possible without running off the gel. An optimal run will allow the glycolate-ended fragments to be well resolved from the phosphate-ended fragments. On a $20 \%$ sequencing gel, the bromphenol blue migrates as if it were an 8-nucleotide DNA fragment while the xylene cyanol migrates as if it were 28 nucleotides long.

14. Dismantle the electrophoresis apparatus, allow the glass plates to cool to room temperature, and then pry the plates apart.

Pry the plates apart carefully to avoid ripping the gel. Scrupulous cleaning of the glass plates is essential, with regular overnight soaking in $1 \mathrm{M} \mathrm{NaOH}$. It is often helpful to coat one of the plates with a silanizing reagent such as Sigmacote (Sigma).

15. Place the gel and its attached plate into a tray containing a sheet of Whatman 3MM paper and enough fixing solution to cover the gel, and gently agitate until the gel detaches from the plate and floats freely in the solution.

If the gel is to be dried, fixation is essential, since $20 \%$ sequencing gels will crack unless soaked in the fixation solution to remove the urea. Alternatively, the wet gel on its plate can be wrapped in plastic wrap and exposed to X-ray film or a phosphor imager plate. However, the thickness of the wet gel will reduce the resolution of the sequencing gel by increasing the fuzziness of the bands.

16. Carefully slide the glass plate out from underneath the gel, allowing the gel to settle onto the Whatman paper, and remove the fixation solution using vacuum suction.

While removing the fixation solution from the tray, use gloved hands to keep the gel positioned over the Whatman paper.

17. Carefully lift the paper out of the tray and dry it in a gel drier set to ramp slowly up to $70^{\circ} \mathrm{C}$.

Do not break the vacuum until the gel is completely dry, or the gel will crack extensively.

The gel is dry if the entire surface is hot to the touch and the gel no longer has any perceptible thickness; cool spots represent evaporating water.

18. Remove the dried gel from the drier and wrap it in plastic wrap for exposure to X-ray film or a phosphor imager plate.

The length of exposure will vary depending on the quantity of radioactivity. An overnight exposure of X-ray film should be adequate for a gel containing lanes with 10,000 to 20,000 cpm of radioactivity; shorter times are needed for a phosphor imager plate.

As illustrated in Figure 10.8.2, phosphoglycolate-ended DNA fragments in the control lane will appear as a band migrating 1/4 nucleotide faster than the phosphate-ended fragment co-migrating with the Maxam-Gilbert sequencing standard. Treatment with hydrazine converts the 4'-keto-1'-aldehyde abasic site to a strand break with a phosphopyridazine residue attached to the $3^{\prime}$ end. The phosphopyridazine-ended fragment migrates 1 to 2 nucleotides more slowly than the phosphate-ended fragment (Fig. 10.8.2). Putrescine cleaves all types of abasic sites (simple and oxidized; Lindahl and Andersson, 1972; Dedon et al., 1992) to phosphate-ended fragments that co-migrate with the phosphate-ended fragments of the Maxam-Gilbert sequencing reactions.

BASIC PROTOCOL 2

Analysis of Oxidized DNA

Fragments by Gel Electrophoresis

\subsection{4}

\section{DETERMINATION OF 5'-OXIDATION OF DEOXYRIBOSE}

As with $4^{\prime}$-oxidation, oxidation of the $5^{\prime}$ position of deoxyribose results in the formation of either of two sets of products, as shown in Figure 10.8.1. One set consists of a formylphosphate residue attached to the $3^{\prime}$ end of the broken DNA strand. The 


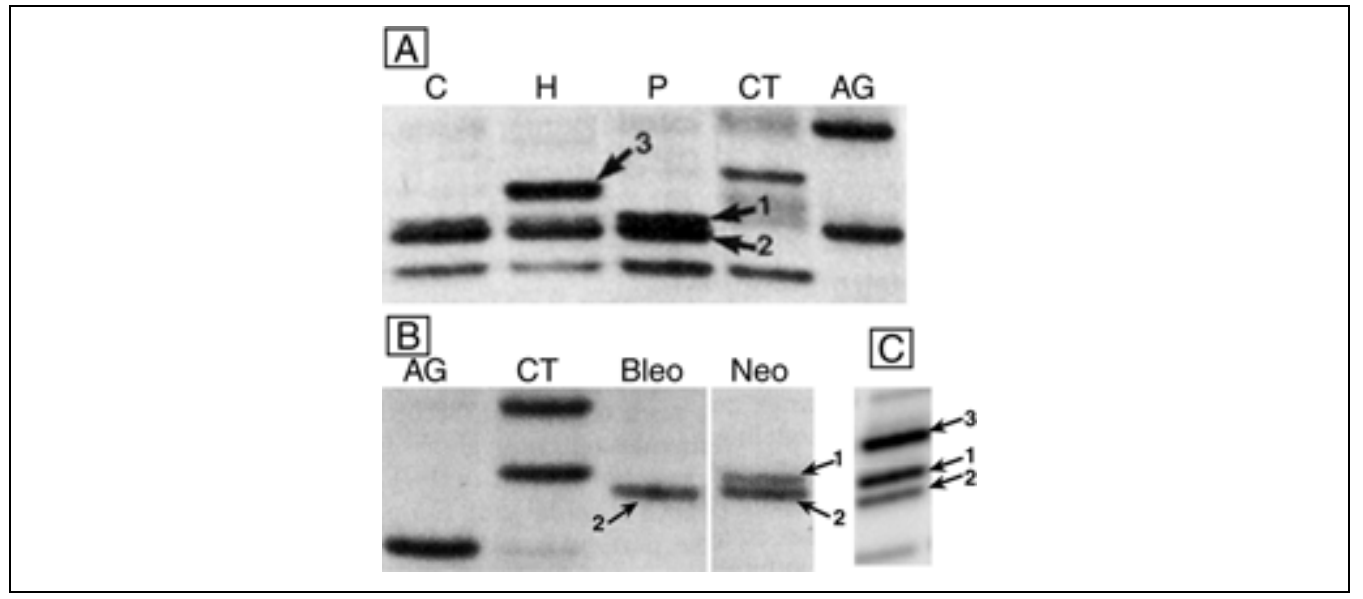

Figure 10.8.2 Gel electrophoretic analysis of the products formed by oxidation of the 4' position of deoxyribose in DNA. All studies were performed with a $5^{\prime}-{ }^{32} \mathrm{P}$-labeled DNA molecule. (A) $20 \%$ sequencing gel analysis of products formed by esperamicin $\mathrm{C}$ cleavage at the A of CAT; the fragment is 21 nucleotides long. Lane C: Control DNA showing a phosphate-ended fragment (1) and a 3'-phosphoglycolate-ended fragment (2). Lane $\mathrm{H}$ : Treatment with hydrazine converts a 4'-keto-1'aldehyde abasic site to a $3^{\prime}$-phosphopyridazine-ended fragment (3). Lane P: Treatment with putrescine converts the abasic site to a $3^{\prime}$-phosphate-ended fragment (1). (B) $20 \%$ sequencing gel analysis of products formed by reaction of bleomycin (Bleo) and neocarzinostatin (Neo) at the T of GTT; the fragment is 10 nucleotides long. Bleomycin produced only a 3'-phosphoglycolate-ended fragment (2) while neocarzinostatin produced both phosphate- (1) and phosphoglycolate-ended (2) fragments. (C) $25 \%$ sequencing gel analysis of products formed by calicheamicin cleavage at the $C$ of AGGATC; the resulting fragment is 34 nucleotides long. The sample was treated with hydrazine, so the gel shows fragments containing phosphate (1), phosphoglycolate (2), and phosphopyridazine (3) residues. Lanes marked AG and CT represent Maxam-Gilbert chemical sequencing standards, all with $3^{\prime}$-phosphate groups.

formyl group is highly reactive and undergoes rapid hydrolysis or transfer to nucleophiles in solution (e.g., Tris; Chin et al., 1987), and so will not be apparent in a sequencing gel. The other product is a strand break containing a nucleoside aldehyde residue attached to the $5^{\prime}$ end (Fig. 10.8.1). This residue causes the fragment to migrate 1 to 4 nucleotides more slowly than a phosphate-ended fragment. The nucleoside aldehyde can be reduced with sodium borohydride to a nucleoside, which migrates slightly more rapidly than the nucleoside aldehyde, though more slowly than a phosphate-ended fragment. The nucleoside aldehyde is also alkali labile, so that treatment of the damaged DNA with $0.5 \mathrm{M}$ piperidine or $100 \mathrm{mM}$ sodium hydroxide will result in removal of the nucleoside aldehyde and formation of a phosphate-ended fragment.

CAUTION: Piperidine is a toxic chemical. It should be handled with gloves, in a fume hood, and disposed of properly. Methods of disposal may vary between different institutions. Consult with the institution's environmental safety office for the preferred means of storage and disposal of piperidine stock solutions.

\section{Materials}

$3^{\prime}-{ }^{32} \mathrm{P}$-end-labeled DNA or duplex oligonucleotide (e.g., see CPMB UNIT 3.6)

1 M HEPES buffer, $\mathrm{pH} 7$

$1 \mathrm{M}$ sodium borohydride (prepare immediately before use)

$0.5 \mathrm{M}$ piperidine (freshly prepared)

$8 \%(\mathrm{w} / \mathrm{v})$ polyacrylamide gel, $0.4 \mathrm{~mm}$ thick, containing urea and TBE electrophoresis buffer

$90^{\circ} \mathrm{C}$ water bath

Purification and Analysis of Synthetic Nucleic Acids and Components 
Additional reagents and equipment for determination of 4'-oxidation of DNA (see Basic Protocol 1)

\section{Perform DNA damage and chemical derivatization}

1. Proceed with the DNA damage reaction as described above (see Basic Protocol 1, steps 1 to 5 ).

2. Precipitate the DNA in one of the $10-\mu \mathrm{L}$ portions as described (see Basic Protocol 1, step 3); this is the control sample.

\section{Reduce DNA in one sample with sodium borohydride}

3. To one of the $10-\mu \mathrm{L}$ portions, add $35 \mu \mathrm{L}$ water and $5 \mu \mathrm{L}$ of 1 M HEPES buffer with mixing.

4. Add $2.5 \mu \mathrm{L}$ of freshly prepared $1 \mathrm{M}$ sodium borohydride and incubate $15 \mathrm{~min}$ on ice.

5. Repeat the addition of another $2.5-\mu \mathrm{L}$ aliquot of freshly prepared $1 \mathrm{M}$ sodium borohydride and incubate the sample for $15 \mathrm{~min}$ on ice.

6. Precipitate the DNA by adding $4 \mu \mathrm{L}$ of $3 \mathrm{M}$ sodium acetate and $150 \mu \mathrm{L}$ of $100 \%$ ethanol, and then process the DNA as described (see Basic Protocol 1, steps $3 \mathrm{~b}$ and $3 c)$. Dry sample under vacuum.

The sodium borohydride contributes a $100 \mathrm{mM}$ concentration of sodium, so add only enough $3 \mathrm{M}$ sodium acetate to bring the sodium concentration to $300 \mathrm{mM}$ for the ethanol precipitation. Alternatively, the DNA can be desalted by passage over a Sephadex G-25 spin column and purified by ethanol precipitation.

\section{Treat DNA in one sample with piperidine}

7. Evaporate the third $10-\mu \mathrm{L}$ portion of the damaged DNA to dryness under vacuum, resuspend the DNA in $50 \mu \mathrm{L}$ of $0.5 \mathrm{M}$ piperidine, and heat the sample at $90^{\circ} \mathrm{C}$ for 15 min.

8. Evaporate the piperidine solution from sample under vacuum and resuspend the DNA in $10 \mu \mathrm{L}$ water. Repeat the evaporation and addition of water twice more, ending with a dried sample after the third evaporation.

\section{Load and run sequencing gel}

9. Resuspend the DNA from steps 2,6 , and 8 each in $4 \mu \mathrm{L}$ of formamide sequencing gel loading buffer without $\mathrm{NaOH}$.

10. Load and run an $8 \%$ sequencing gel as described (see Basic Protocol 1; steps 10 to 18).

The large shifts in DNA fragment mobility associated with the nucleoside aldehyde residue and its reduced nucleoside form usually do not require high resolution (e.g., 20\%) sequencing gels for analysis.

As illustrated in the control lane of Figure 10.8.3, a DNA fragment possessing a nucleoside-5'-aldehyde at the $5^{\prime}$ end will migrate 1 to 4 nucleotides more slowly than the corresponding phosphate-ended fragment (i.e., a fragment lacking the nucleoside aldehyde). Reduction of the nucleoside-5'-aldehyde with sodium borohydride results in the formation of a nucleoside-ended DNA fragment that migrates slightly faster than the nucleoside-aldehyde-ended fragment. Piperidine treatment results in removal of the nucleoside-aldehyde moiety and leaves a phosphate-ended fragment.

Analysis of Oxidized DNA Fragments by Gel Electrophoresis 


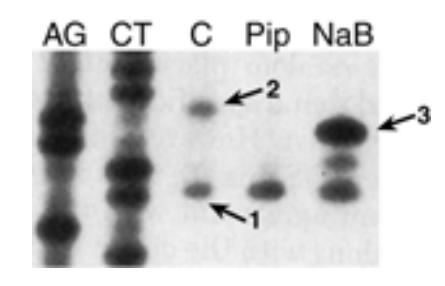

Figure 10.8.3 Gel electrophoretic analysis of the products formed by oxidation of the 5' position of deoxyribose in DNA. This is an $8 \%$ polyacrylamide sequencing gel containing the products formed by neocarzinostatin cleavage at the T of ACT. Lane C: Control DNA showing a phosphate-ended fragment (1) and a fragment possessing a nucleoside- 5 '-aldehyde aldehyde (2). Lane Pip: Treatment with piperidine cleaves the nucleoside-5'-aldehyde to produce a phosphate-ended fragment. Lane NaB: Reduction of the nucleoside-5'-aldehyde with sodium borohydride produces a nucleoside-ended fragment (3) that migrates slightly ahead of the nucleoside aldehyde.

\section{DETERMINATION OF 3'-OXIDATION OF DEOXYRIBOSE}

As shown in Figure 10.8.1, oxidation of the $3^{\prime}$ position of deoxyribose results in the formation of a phosphoglycoaldehyde residue attached to the $3^{\prime}$ end of the resulting DNA fragment. The glycoaldehyde can be reduced with sodium borohydride to glycol, which causes the DNA fragment to migrate slightly faster than the glycoaldehyde-ended fragment, but more slowly than the corresponding phosphate-ended fragment. Oxidation of the glycoaldehyde with sodium chlorite results in the formation of a glycolate residue that causes the fragment to migrate slightly faster than the corresponding 3 '-phosphateended fragment as discussed in Basic Protocol 1.

CAUTION: Piperidine is a toxic chemical. It should be handled with gloves, in a fume hood, and disposed of properly. Methods of disposal may vary between different institutions. Consult with the institution's environmental safety office for the preferred means of storage and disposal of piperidine stock solutions.

\section{Materials}

$0.1 \mathrm{M}$ sodium chlorite in $20 \mathrm{mM}$ potassium phosphate buffer, $\mathrm{pH} 4$ (see APPENDIX $2 A$ for buffer)

$0.1 \mathrm{M}$ sodium sulfite $\left(\mathrm{Na}_{2} \mathrm{SO}_{3}\right)$

Additional reagents and equipment as for $4^{\prime}$ - and $5^{\prime}$-oxidation of DNA (see Basic Protocols 1 and 2)

\section{Prepare damaged DNA for chemical derivatization}

1. Proceed with the DNA damage reaction as described above (see Basic Protocol 1, steps 1 to 3$)$.

2. Dry the sample under vacuum and resuspend the DNA in $40 \mu \mathrm{L}$ of deionized water. Split the solution into four $10-\mu \mathrm{L}$ aliquots.

3. Precipitate the DNA in one of the $10-\mu \mathrm{L}$ portions (see Basic Protocol 1, step 3); this is the control sample.

\section{Oxidize DNA in one sample with sodium chlorite}

4. To one of the $10-\mu \mathrm{L}$ portions, add $1 \mu \mathrm{L}$ of $0.1 \mathrm{M}$ sodium chlorite solution and incubate at room temperature for $6 \mathrm{hr}$.

5. Quench the reaction by adding $1 \mu \mathrm{L}$ of $0.1 \mathrm{M}$ sodium sulfite.

Purification and Analysis of Synthetic Nucleic Acids and Components

\subsection{7}


6. Remove salts by adding $30 \mu \mathrm{L}$ of water and passing the sample over a Sephadex G-25 spin column.

7. Precipitate the DNA from the column filtrate as described (see Basic Protocol 1, step $3)$.

\section{Reduce DNA in one sample with sodium borohydride}

8. Treat one of the $10-\mu \mathrm{L}$ DNA aliquots with sodium borohydride as described above (see Basic Protocol 2, steps 3 to 6).

\section{Convert phosphoglycoaldehyde residues to phosphate-ended fragments}

9. Treat the fourth $10-\mu \mathrm{L}$ portion with piperidine as described (see Basic Protocol 2, steps 7 and 8).

\section{Load and run sequencing gel}

10. Resuspend the DNA in samples from steps 3, 7, 8, and 9 in $4 \mu \mathrm{L}$ of formamide sequencing gel loading buffer without $\mathrm{NaOH}$.

11. Load and run a $20 \%$ sequencing gel as described (see Basic Protocol 1, steps 10 to 18).

As illustrated in the control lane of Figure 10.8.4, a 16-nucleotide DNA fragment possessing a 3'-phosphoglycoaldehyde residue will migrate $\sim 1$ nucleotide more slowly than the corresponding phosphate-ended fragment (i.e., a fragment lacking the phosphoglycoaldehyde). Reduction of the phosphoglycoaldehyde with sodium borohydride results in the formation a 3'-phosphoglycol-ended DNA fragment that migrates slightly faster than the 3'-phosphoglycoaldehyde-ended fragment but more slowly than the corresponding 3'phosphate-ended fragment. Oxidation of the glycoaldehyde to glycolic acid with sodium chlorite results in the formation of a fragment that migrates faster than the corresponding 3'-phosphate-ended fragment. This behavior was described for products of oxidation of the $4^{\prime}$ position of deoxyribose in Basic Protocol 1. Piperidine treatment results in removal of the glycoaldehyde moiety and leaves a phosphate-ended fragment.

Analysis of Oxidized DNA Fragments by Gel Electrophoresis

\section{8 .8}

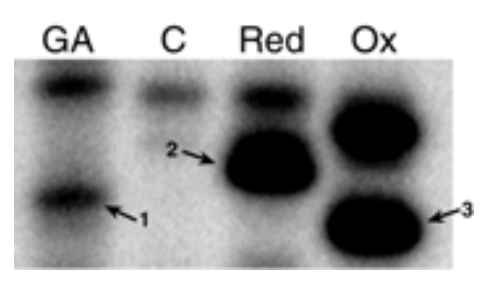

Figure 10.8.4 Gel electrophoretic analysis of the products formed by oxidation of the 3' position of deoxyribose in DNA. This is a $20 \%$ polyacrylamide sequencing gel containing a synthetic $16-m e r$ oligonucleotide possessing a $3^{\prime}$-phosphoglycoaldehyde residue and the associated products of chemical derivatization. Lane GA: $3^{\prime}$-phosphate-ended Maxam-Gilbert chemical sequencing standards for $\mathrm{G}$ and $\mathrm{A}$; the band marked 1 is the $3^{\prime}$-phosphate-ended 16-mer fragment. Lane C: Control DNA fragment with a 3'-phosphoglycoaldehyde residue. Lane Red: Treatment of the glycoaldehydeended fragment with sodium borohydride produces a $3^{\prime}$-phosphoglycol-ended fragment (2). Lane Ox: Oxidation of the glycoaldehyde-ended fragment with sodium chlorite produces a $3^{\prime}$-phosphoglycolate-ended fragment (3). The other band present in this lane represents an unidentified intermediate in chlorite oxidation of 3'-phosphoglycoaldehyde. The product can be avoided by longer incubation with chlorite. 


\section{COMMENTARY}

\section{Background Information}

The experiments presented in this unit are intended as a first step in defining the chemistry of deoxyribose oxidation produced by hydrogen atom abstraction at the $3^{\prime}-, 4^{\prime}-$, and $5^{\prime}$-positions. The technique exploits the unique shifts in polyacrylamide gel migration of DNA fragments with damage residues attached to the $3^{\prime}$ and $5^{\prime}$ ends. The change in mobility is judged against the phosphate-ended fragments generated by Maxam-Gilbert chemical sequencing reactions. Gel mobility shift assays have been used successfully to define the deoxyribose oxidation chemistry produced by agents such as the enediyne antibiotics neocarzinostatin (Dedon and Goldberg, 1990; Kappen et al., 1991), esperamicin (Christner et al., 1992; Yu et al., 1994), calicheamicin (Hangeland et al., 1992; Dedon et al., 1993), and C-1027 (Xu et al., 1994), as well as the antitumor agent bleomycin (Steighner and Povirk, 1990), rhodium complexes (Sitlani et al., 1992), ionizing radiation (Henner et al., 1983), and Fe-EDTA (Balasubramanian et al., 1998).

Gel electrophoretic analysis of deoxyribose oxidation products finds utility in several aspects of DNA damage research. The first is primary estimation of the DNA damage chemistry. The position of deoxyribose oxidation by a DNA-cleaving agent with limited sequence selectivity (i.e., nonrandom cleavage) can be estimated using the mobility shift assay with chemical derivatization. To avoid the ambiguities associated with a single gel shift observation, each protocol involves several chemical derivatization steps to fully characterize the products associated with oxidation at each position in deoxyribose. Even with the inclusion of additional chemical derivatization steps, however, the gel shift assay cannot replace the rigor of complete chemical characterization of the deoxyribose degradation products. Furthermore, the assay does not provide definitive evidence for the deoxyribonolactone abasic site produced by $1^{\prime}$-hydrogen atom abstraction from deoxyribose (Yu et al., 1994), though this abasic site is resistant to hydrazine derivatization and sensitive to putrescine cleavage (Yu et al., 1994).

Once the chemical identity of the damage has been established, a second application involves quantitative and qualitative comparison of deoxyribose oxidation chemistry at various damage sites. For example, the enediyne antibiotic neocarzinostatin cleaves DNA to pro- duce lesions caused by both $4^{\prime}$ - and $5^{\prime}$-oxidation at the same site (Kappen et al., 1991). The shuttling between the $4^{\prime}$ and $5^{\prime}$ positions can be directed by site-specific deuterium labeling, with quantitation of the isotope effect defined by gel shift analysis of the various products of $4^{\prime}$ - and 5'-oxidation chemistry (Kappen et al., 1991).

A third application involves an assessment of the partitioning of chemical reactions occurring at a single site in deoxyribose. For example, the chemistry of a bleomycin-induced $4^{\prime}$ hydrogen atom undergoes abstraction partitioning along two pathways to produce either a phosphoglycolate-ended fragment or a $4^{\prime}$ keto-1'-aldehyde abasic site (Fig. 10.8.1). This partitioning varies as a function of the oxygen concentration since the glycolate is oxygen dependent while the abasic site does not require oxygen for its formation (McGall et al., 1987). Another example involves neocarzinostatin and calicheamicin. These enediynes produce double-strand lesions at several sites in DNA with $4^{\prime}$-deoxyribose oxidation on one strand producing both glycolate and the abasic site. However, in the single-strand lesions produced at the same site, the sole product is glycolate (Dedon et al., 1993). This suggests that the partitioning of enediyne-mediated 4'-chemistry involves interaction between lesions on each strand. Combined with the sensitivity of phosphor imager analysis, the gel shift assay allows sensitive and quantitative determination of deoxyribose oxidation chemistry at multiple sites and within a single site.

\section{Critical Parameters}

There are several factors critical to the successful application of the gel shift technique. An important factor is the length of the sequencing gel used to resolve glycolate- from phosphate-ended fragments. A $40-\mathrm{cm}$ sequencing gel will allow resolution of these species for DNA fragments up to 30 to $40 \mathrm{bp}$, with migration of the fragments of interest at least to the bottom quarter of the gel. Better resolution of 30- to 40-bp glycolate- and phosphateended fragments can be achieved on a $60-\mathrm{cm}$ gel, though this may require running times of 24 to $48 \mathrm{hr}$.

Interpretation of the bands representing cleavage products also requires a reasonable separation of cleavage sites. Optimal results are obtained with an agent that cleaves DNA at sites separated from one another by more than 3 to
Purification and Analysis of Synthetic Nucleic Acids and Components 
4 nucleotides. In the "random" cleavage patterns produced by ionizing radiation and $\mathrm{Fe}$ EDTA, the proximity of glycolate-ended DNA fragments to their phosphate-ended counterparts permits ready identification of these fragments. However, nucleoside aldehyde residues and phosphopyridazine derivatives migrate several nucleotides distant to their phosphateended counterparts and there is more significant variation in their mobility as a function of length relative to glycolate-ended fragments. This makes their identification difficult due to the complexity of the band pattern of closely spaced fragments.

The stability of several of the deoxyribose oxidation products presents a problem for quantitative studies. The abasic sites and the nucleoside aldehyde residue are susceptible to degradation at alkaline $\mathrm{pH}$ and elevated temperature. To retain these lesions, samples should be processed quickly, with the DNA samples kept on ice and manipulations minimized to avoid degradation of the labile structures. It is important to add HEPES buffer to avoid the alkaline $\mathrm{pH}$ generated during the sodium borohydride reduction.

Finally, it is important to use freshly prepared DNA substrates for these studies. Radiolytic degradation of the DNA will lead to a high background of strand breaks possessing a variety of fragment end-chemistries. Minimization of ${ }^{32} \mathrm{P}$-mediated degradation can be achieved by (1) preparing the DNA within 24 hr of use; (2) storing the DNA in Tris, HEPES, or other amine-containing buffer; and (3) diluting the DNA as much as possible for storage.

\section{Troubleshooting}

Several problems may be encountered during the experiments. Inadequate resolution of DNA fragments can be solved by decreasing the length of the DNA substrate under study or by increasing the length of the gel as discussed above. Excessive background due to cleavage produced by ${ }^{32} \mathrm{P}$ can be handled by proper storage conditions (see Critical Parameters). If salts are not removed adequately by Sephadex chromatography and ethanol precipitation, the sequencing gel will show progressively narrower lanes with fuzzy, poorly resolved bands.

\section{Anticipated Results}

The experiments described in this unit will produce results similar to those shown in Figure 10.8.2, Figure 10.8.3, and Figure 10.8.4. The reader can also review the cited references for other examples of the application of gel mobil- ity analysis to the solution of DNA oxidation chemistry.

\section{Time Considerations}

Preparation of DNA substrates will require one day while performance of the damage reactions and processing of the DNA samples will require an additional day. The length of time required to run the sequencing gels will depend on the length of the DNA fragment. Oligonucleotides of 10 to $30 \mathrm{bp}$ require several hours to adequately resolve glycolate-ended fragments from phosphate-ended fragments on a 40-cm gel; longer DNA fragments necessitate runs of as much as 24 to $48 \mathrm{hr}$ on a $60-\mathrm{cm}$ sequencing gel. Processing of the sequencing gels may require several hours to allow for fixation and drying, with exposure of X-ray film or phosphor imager plates requiring several hours to overnight.

\section{Literature Cited}

Balasubramanian, B., Pogozelski, W.K., and Tullius, T.D. 1998. DNA strand breaking by the hydroxyl radical is governed by the accessible surface areas of the hydrogen atoms of the DNA backbone. Proc. Natl. Acad. Sci. U.S.A. 95:9738-9743.

Chin, D.-H., Kappen, L.S., and Goldberg, I.H. 1987. 3'-Formyl phosphate-ended DNA: High energy intermediate in antibiotic-induced DNA sugar damage. Proc. Natl. Acad. Sci. U.S.A. 84:70707074.

Christner, D.F., Frank, B.L., Kozarich, J.W., Stubbe, J., Golik, J., Doyle, T.W., Rosenberg, I.E., and Krishnan, B. 1992. Unmasking the chemistry of DNA cleavage by the esperamicins: Modulation of 4'-hydrogen abstraction and bistranded damage by the fucose-anthranilate moiety. $J$. Am. Chem. Soc. 114:8763-8767.

Dedon, P.C. and Goldberg, I.H. 1990. Sequencespecific double-strand breakage of DNA by neocarzinostatin within a staggered cleavage site. $J$. Biol. Chem. 265:14713-14716.

Dedon, P.C. and Goldberg, I.H. 1992. Influence of thiol structure on neocarzinostatin activation and expression of DNA damage. Biochemistry 31:1909-1917.

Dedon, P.C., Jiang, Z.-W., and Goldberg, I.H. 1992. Neocarzinostatin-mediated DNA damage in a model AGT ACT site: Mechanistic studies of thiol-sensitive partitioning of $\mathrm{C}^{\prime}{ }^{\prime} \mathrm{DNA}$ damage products. Biochemistry 31:1917-1927.

Dedon, P.C., Salzberg, A.A., and Xu, J. 1993. Exclusive production of bistranded DNA damage by calicheamicin. Biochemistry 32:3617-3622.

Hangeland, J.J., De Voss, J.J., Heath, J.A., Townsend, C.A., Ding, W.-D., Ashcroft, J.S., and Ellestad, G.A. 1992. Specific abstraction of the $5^{\prime}(\mathrm{S})$ - and $4^{\prime}$-deoxyribosyl hydrogen atoms from DNA by calicheamicin $\gamma_{1}{ }^{\mathrm{I}}$.J. Am. Chem. Soc. 114:9200-9202. 
Henner, W.D., Rodriguez, L.O., Hecht, S.M., and Haseltine, W.A. 1983. Gamma ray induced deoxyribonucleic acid strand breaks: $3^{\prime}$ glycolate termini. J. Biol. Chem. 258:711-713.

Kappen, L.S., Goldberg, I.H., Frank, B.L., Worth, L.J., Christner, D.F., Kozarich, J.W., and Stubbe, J. 1991. Neocarzinostatin-induced hydrogen atom abstraction from $\mathrm{C}-4^{\prime}$ and $\mathrm{C}-5^{\prime}$ of the $\mathrm{T}$ residue at a $\mathrm{d}(\mathrm{GT})$ step in oligonucleotides: Shuttling between deoxyribose attack sites based on isotope selection effects. Biochemistry 30:20342042.

Lindahl, T. and Andersson, A. 1972. Rate of chain breakage at apurinic sites in double-stranded deoxyribonucleic acid. Biochemistry 11:36183623.

McGall, G., Rabow, L., Stubbe, J., and Kozarich, J.W. 1987. Incorporation of ${ }^{18} \mathrm{O}$ into glycolic acid obtained from the bleomycin-mediated degradation of DNA: Evidence for 4'-radical trapping by ${ }^{18} \mathrm{O}_{2}$. J. Am. Chem. Soc. 109:2836-2837.

Sitlani, A., Long, E.C., Pyle, A.M., and Barton, J.K. 1992. DNA photocleavage by phenanthrenequinone diimine complexes with rhodium (III): Shape-selective recognition and reaction. J. Am. Chem. Soc. 114:2303-2312.
Steighner, R.J. and Povirk, L.F. 1990. Bleomycininduced DNA lesions at mutational hot spots: Implications for the mechanism of double-strand cleavage. Proc. Natl. Acad. Sci. U.S.A. 87:83508354.

Stubbe, J. and Kozarich, J.W. 1987. Mechanisms of bleomycin-induced DNA degradation. Chem. Rev. 87:1107-1136.

Xu, Y.-J., Zhen, Y.-S., and Goldberg, I.H. 1994. C1027 chromophore, a potent new enediyne antitumor antibiotic, induces sequence-specific double-strand DNA cleavage. Biochemistry 33:5947-5954.

Yu, L., Golik, J., Harrison, R., and Dedon, P. 1994. The deoxyfucose-anthranilate of esperamicin A1 confers intercalative DNA binding and causes a switch in the chemistry of bistranded DNA lesions. J. Am. Chem. Soc. 116:9733-9738.

Contributed by Mohamad Awada and Peter C. Dedon

Massachusetts Institute of Technology

Cambridge, Massachusetts
Purification and Analysis of Synthetic Nucleic Acids and Components 